\title{
NCCN Guidelines Distress Management Problem List Screening Tool Version 1.2011
}

National Cancer Institute

\section{Source}

National Cancer Institute. NCCN Guidelines Distress Management Problem List

Screening Tool Version 1.2011. NCI Thesaurus. Code C107157.

A screening tool developed by the National Comprehensive Cancer Network (NCCN)

Distress Management Panel used to identify patient problems in five categories. 